\title{
Hypertrophic reversed palmaris longus muscle: a cadaveric finding
}

\author{
L. Pires ${ }^{1}$, J.-P. Perissé ${ }^{1}$, G.C.S. Araújo ${ }^{2}$, J. Manaia ${ }^{1}$, A. Fonseca Júnior ${ }^{1}$, M.A. Babinski ${ }^{1}$ \\ ${ }^{1}$ Morphology Department, Universidade Federal Fluminense, Rua Professor Ernani Mello, Niterói, Brazil \\ 2SARAH Hospital, Brasilia, Brazil
}

[Received: 7 October 2017; Accepted: 18 October 2017]

\begin{abstract}
Variations of the forearm musculature are vastly described in the literature. The palmaris longus muscle is one of the most variable structures of the human body. It usually arises from the medial epicondyle of the humerus and inserts itself into the palmar aponeurosis. Anatomy textbooks and recent papers state that this muscle may act as a weak wrist flexor. The present work aims to report an anatomical variation where the palmaris longus muscle was abnormally hypertrophied and was completely fleshy throughout the whole forearm. Anatomical variations of the palmaris longus may induce symptoms of neurovascular bundle compression, especially of the median nerve. The palmaris longus muscle may be used in tendon graft or muscle graft, due to its lack of apparent function. Furthermore, it is one of the anatomical landmarks for local anaesthesia procedures. (Folia Morphol 2018; 77, 2: 403-405)
\end{abstract}

Key words: anatomical variations, palmaris longus muscle, fully fleshy, hypertrophied

\section{INTRODUCTION}

The palmaris longus muscle (PLM) is considered the most variable muscle in the human body. Despite that, it usually originates from the medial epicondyle of the humerus as a fusiform muscle belly. Then, at the middle third of the forearm it turns into a long tendon that inserts itself into the palmar aponeurosis $[7,11,20,21]$.

It acts as a weak wrist flexor and it puts tension into the palmar aponeurosis, although there is a debate regarding its actual function and significance $[1,11,13,20,21]$. It is innervated by the median nerve $(\mathrm{MN})[11,21]$.

Variations of the PLM are known to be the cause of neurovascular bundle compression syndrome, specifically on the $\mathrm{MN}$ at the carpal tunnel and the ulnar nerve (UN) at the Guyon's canal [3, 11, 12]. Nerve entrapment and effort-related compartment syndrome has been associated with the presence of a reversed PLM (RPLM) $[17,20]$.

Due to its lack of functional capacity, the PLM can be used as graft in reconstructive surgeries. Furthermore, knowledge of its anatomy is essential, as it is used as a landmark for local anaesthesia of the MN $[12,17]$.

The present work aims to report the presence of an abnormally large fleshy PLM and discuss its anthropological and clinical significance.

\section{CASE REPORT}

A male cadaver with no known cause of death was fixated with a phenol solution and dissected for teaching purposes. Its right forearm presented a remarkable variation of the RPLM. The referred muscle was abnormally enlarged and was mainly composed of muscle tissue. It originated by a tendinous slip and became fully fleshy (Fig. 1). 


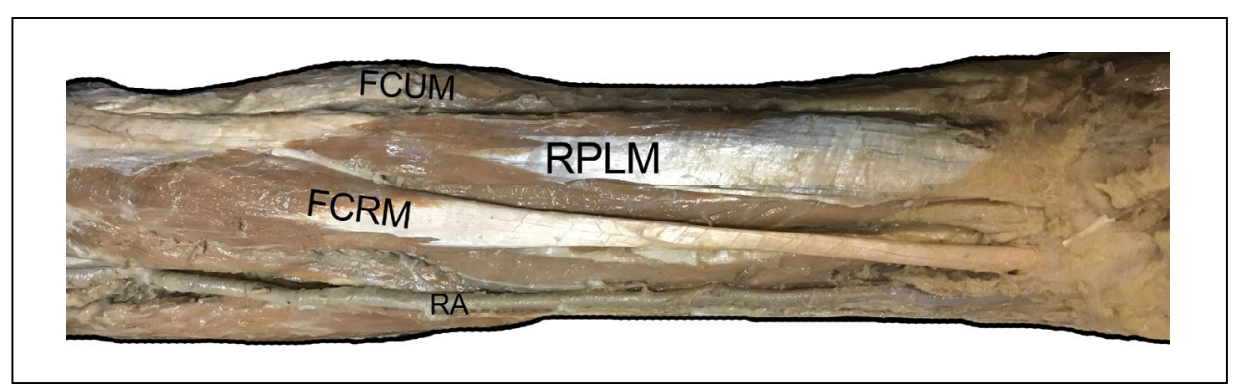

Figure 1. Dissection of the right forearm. Anterior view; FCRM — flexor carpi radialis muscle; FCUM — flexor carpi ulnaris muscle; $\mathrm{RA}$ — radial artery; RPLM — reverse palmaris longus muscle.

It had regular origins and attachments, although it also inserted itself into the flexor retinaculum. The ulnar artery ran deep to the muscle. The muscle was $25.3 \mathrm{~cm}$ long and was $1.83 \mathrm{~cm}$ thick.

\section{DISCUSSION}

On the upper limb, the ventral mass gives origin to the muscles that flexes or pronates the forearm, while the dorsal mass originates the extensor and supinator components. One of the main theories is that those masses begin to differentiate into the muscles through apoptotic mechanisms and growth factors, thus, giving shape and appearance of the muscles $[5,18]$.

Hence, variations of the limb musculature are usually attributed to failure during differentiation process, either by erratic apoptotic mechanisms or lack of stimuli to perform apoptosis. This was hypothesised in earlier days by Le Double [10], and confirmed by further embryological studies [18].

In reptiles and lower species this mass is less individualised, as these animals do not need to perform specialised movements of the forearm [10].

Variations of the forearm muscles are vastly described in the literature $[10,21,22]$.

The PLM itself is one of the most variable muscles in the human body. Its duplication, triplication and bifurcation have been described. Likewise, changes in its shape, abnormal insertions, accessory slips to adjacent muscles and its absence has also been reported in the literature $[1,7,10,11,13-15,17,18$, 23]. The RPLM is a rare variation of the PLM, although it has been consistently described in the literature $[3,6,10-13,15,17,19]$. Despite that, the presence of an abnormally large and fully fleshed PLM as reported herein was not previously described in the literature, although three similar cases were described $[2,13,16]$.
The PLM is present in amphibians. It is fusiform in bats, and in an elephant dissected by Greenwood, according to Le Double [10] the PLM was long and fleshy until it reached the carpal region. In rats, the PLM is blended with the proximal portion of the flexor carpi ulnaris muscle [8].

Historical data points out that the PLM absence was first described by Columbus in 1593 [see 10]. The fact that the PLM possess no significant action and it is a vestigial muscle explains the high rates of its absence [10]. Furthermore, recent studies showed that these rates are indeed increasing over the years [1].

Testut and Latarjet (1958) [21] comments that the PLM is never absent in lesser apes such as the gibbon (Hylobatidae), although it can be absent in chimpanzees (Pan troglodytes) and gorillas (Gorilla gorilla) in a proportion of 5 to 100 and 85 to 100 , respectively.

There are speculations regarding heredity of the PLM absence [21], although there are only a few studies that deal with this hypothesis [1]. Despite that, it is stated that PLM absence is of recessive character, while presence is a dominant one $[1,11]$, although some studies reports the opposite [11].

Furthermore, beliefs that the palmar aponeurosis could be considered as an expansion of the PLM tendon was reported in descriptive anatomy textbooks [21].

Neurovascular bundle compression is one of the main concerns and most significant clinical aspects of muscle variations in the forearm. The excessive pressure on nerves caused by supernumerary or hypertrophic muscles can cause pain and numbness of the forelimb $[3-5,9,11,22]$. The RPLM has been associated with $M N$ compression $[2,3,12,17,19]$.

Thus, the presence of an abnormally large and fleshy PLM is very likely to provoke compressive syndrome, and in the case presented herein the UN may also have been one of the structures affected due to its insertion on the roof of the ulnar canal (Guyon's canal). 


\section{Acknowledgements}

We wish to thank the donor and their families in respect for the cadaver used in present study.

\section{REFERENCES}

1. Barkáts N. Change of the agenesis rate of palmaris longus muscle in an isolated village in Ukraine. Folia Morphol. 2015; 74(4): 470-474, doi: 10.5603/FM.2015.0109, indexed in Pubmed: 26620507.

2. Barkáts N. Hypertrophy of palmaris longus muscle, a rare anatomic aberration. Folia Morphol. 2015; 74(2): 262-264, doi: 10.5603/FM.2015.0040, indexed in Pubmed: 26050817.

3. Bhashyam AR, Harper CM, lorio ML. Reversed palmaris longus muscle causing volar forearm pain and ulnar nerve paresthesia. J Hand Surg Am. 2017; 42(4): 298.e1-298.e5, doi: 10.1016/j.jhsa.2016.11.016, indexed in Pubmed: 27964899.

4. Christos L, Konstantinos N, Evagelos P. Revision of Carpal Tunnel Release due to Palmaris Longus Profundus. Case Rep Orthop. 2015; 2015: 616051, doi: 10.1155/2015/616051, indexed in Pubmed: 26075127.

5. Cıftçıoğlu E, Kopuz C, Corumlu U, et al. Accessory muscle in the forearm: a clinical and embryological approach. Anat Cell Biol. 2011; 44(2): 160-163, doi: 10.5115/ acb.2011.44.2.160, indexed in Pubmed: 21829760.

6. Depuydt $\mathrm{KH}$, Schuurman $\mathrm{AH}$, Kon M. Reversed palmaris longus muscle causing effort-related median nerve compression. J Hand Surg Br. 1998; 23(1): 117-119, indexed in Pubmed: 9571503.

7. Dimitriou I, Katsourakis A, Natsis K, et al. Palmaris Longus Muscle's Prevalence in Different Nations and Interesting Anatomical Variations: Review of the Literature. J Clin Med Res. 2015; 7(11): 825-830, doi: 10.14740/jocmr2243w, indexed in Pubmed: 26491493.

8. Diogo R, Abdala V, Aziz MA, et al. From fish to modern humans--comparative anatomy, homologies and evolution of the pectoral and forelimb musculature. J Anat. 2009; 214(5): 694-716, doi: 10.1111/j.1469-7580.2009.01067.x, indexed in Pubmed: 19438764.

9. Fröber R, Linss W. Anatomic bases of the forearm compartment syndrome. Surg Radiol Anat. 1994; 16(4): 341-347, indexed in Pubmed: 7725187.

10. Le Double A-F. Traité des variations du système musculaire de l'homme et de leur signification au point de vue de I'anthropologie zoologique. Schleischer Fréres. Paris 1897.
11. Mathew AJ, Sukumaran TT, Joseph S. Versatile but temperamental: a morphological study of palmaris longus in the cadaver. J Clin Diagn Res. 2015; 9(2): AC01-AC03, doi: $10.7860 / J C D R / 2015 / 11212.5542$, indexed in Pubmed: 25859436.

12. Murabit A, Gnarra M, Mohamed A. Reversed palmaris longus muscle: Anatomical variant - case report and literature review. Can J Plast Surg. 2013; 21(1): 55-56, indexed in Pubmed: 24431941.

13. Natsis K, Didagelos M, Manoli Sm, et al. Fleshy palmaris longus muscle - a cadaveric finding and its clinical significance: a case report. Hippokratia. 2012; 16(4): 378-380, indexed in Pubmed: 23935323.

14. Natsis K, Levva S, Totlis T, et al. Three-headed reversed palmaris longus muscle and its clinical significance. Ann Anat. 2007; 189(1): 97-101, doi: 10.1016/j.aanat.2006.07.008, indexed in Pubmed: 17319615.

15. Pai MM, Prabhu LV, Nayak SR, et al. The palmaris longus muscle: its anatomic variations and functional morphology. Rom J Morphol Embryol. 2008; 49(2): 215-217, indexed in Pubmed: 18516329.

16. Ramesh P, Aswin P, Gupta PA. fleshy palmaris longus muscle. Anatomy Journal of Africa. 2015; 4(1): 436-439.

17. Salgado G, Cantín M, Inzunza O, et al. Bilateral reversed palmaris longus muscle: a rare anatomical variation. Folia Morphol. 2012; 71(1): 52-55, indexed in Pubmed: 22532187.

18. Schoenwolf G, Bleyl S, Brauer P, Francis-West P. Larsen's Human Embryology. 5th ed. Churchill Livingstone, Philadelphia 2014: 576.

19. Schuurman AH, van Gils AP. Reversed palmaris longus muscle on MRI: report of four cases. Eur Radiol. 2000; 10(8): 1242-1244, doi: 10.1007/s003300000314, indexed in Pubmed: 10939482.

20. Souza C, Pires L, Figueiredo L, et al. Palmaris inversus muscle: a case report with clinical and surgical discussions. Int J Anat Res. 2017; 5(4.1): 4500-4503, doi: 10.16965/ ijar.2017.383.

21. Testut L, Latarjet A. Tratado de Anatomía Humana. 8th ed. Salvat, Barcelona 1958.

22. Tubbs RS, Shoja MM, Loukas M. editors. Bergman's Comprehensive Encyclopedia of Human Anatomic Variation. Wiley-Blackwell, Philadelphia 2016.

23. Yildiz M, Sener M, Aynaci O. Three-headed reversed palmaris longus muscle: a case report and review of the literature. Surg Radiol Anat. 2000; 22(3-4): 217-219, indexed in Pubmed: 11143317. 